\title{
O campo da saúde suplementar no Brasil à luz da teoria do poder simbólico de Pierre Bourdieu
}

\author{
Paulo Ferreira Vilarinho*
}

\section{Resumo}

Este artigo pretende analisar a evolução dos fatores históricos e institucionais que levaram ao atual quadro da saúde suplementar no Brasil. A análise está fundamentada, principalmente, na teoria do poder simbólico, de Pierre Bourdieu, sendo complementada, nos aspectos não colidentes, pela visão institucional de Anthony Giddens sobre as motivações da gênese dos campos. Além da pesquisa documental, foram realizadas, entre 2002 e 2003, entrevistas abertas cujos depoimentos são analisados de uma perspectiva qualitativa. Foi levado em conta o ponto de vista dos entrevistados, a identificação dos atores que integram o campo e seus respectivos objetivos estratégicos externalizados (inferindo sobre aqueles nem sempre evidentes), bem como, os recursos de poder utilizados para se alcançar tais objetivos, procurando mostrar, pela descrição de fatos historicamente determinantes, a evolução constitutiva do campo.

0 estudo sinaliza que o campo da saúde suplementar se formou a partir de inúmeras ações do Estado, particularmente, após a década de 1970, como conseqüência de uma estratégia alternativa de ampliação da oferta de serviços de saúde à população brasileira. Isso fortaleceu a institucionalização de estruturas isomórficas dotadas de alto grau de interação e uma hierarquia entre valores e crenças, como atributos de um simbolismo inerente ao campo, dentre os quais sobressai 0 símbolo da saúde como intrínseco à cidadania. 0 estudo conclui que a conjugação de fatores como a crescente longevidade da população brasileira, a dificuldade de recolocação da massa de aposentados no mercado de trabalho e 0 continuado processo de concentração da renda nacional - situação agravada pela forte pressão dos custos da tecnologia médica - poderão elitizar o acesso aos serviços de saúde suplementar, o que, futuramente, representará um grave problema para esse sensível segmento da política social do governo brasileiro.

Palavras-chave.: saúde suplementar - Brasil, poder simbólico, Pierre Bourdieu

\section{Abstract}

This article analyzes the evolution of historical and institutional factors that led the Brazilian private health market to its present situation. Its main theoretical basis is the Pierre Bourdieu's symbolic power theory, complemented, in the nonconflictive aspects, by the Anthony Giddens' institutional perspective on the field genesis motivational factors. The research' data were collected through documents and semi structured interviews during 2002-2003 period, involving the qualitative analysis due to understand the field's phenomena under an actors' perspective. The research identifies the several players that integrate the market, their evident strategic goals and those that are not so, besides the powers' resources used to reach them. Thus, it tries to show, through a historic linear description, emphasizing determinant facts, the market's evolutionary constitution.

This study demonstrates that the private health market in Brazil results of several measures by the government, particularly after the 1970's, as a consequence of an alternative strategy aiming to expand the health services. It enforced the institutionalization of isomorphic structures with a strong internal interaction and a hierarchy involving values and beliefs, as characteristics of a symbolism, which is inherent to the field. Among such characteristics, health care stands out as something inherent to the citizenship. Finally, this study considers that the increasing Brazilian population's longevity, the difficulties faced by retirees who intend going back to the labor market and the rising concentration of the national income (the high medical technology costs makes the situation even worse) may restrict access to the private health market. In the future, it will be a serious problem in this very important sector of the Brazilian social policy.

Keywords:: private health - Brasil, simbolic power, Pierre Bourdieu

"Conferencista da Escola Superior de Guerra (ESG/EMFA). E-mail: pvilarinho@ aol.com.

Artigo recebido em outubro de 2004 e aceito em dezembro de 2004. 


\section{Introdução}

Especialmente após a segunda metade do século XX, com a gradativa aceitação da lógica neoliberal pela maioria dos governos ocidentais, verificou-se uma tendência ao fortalecimento do mercado e à redução do papel do Estado nas economias, em contraposição a uma crescente conscientização das pessoas quanto aos direitos sociais, notadamente, aqueles pertinentes às relações de consumo.

O grau de complexidade do campo da saúde fica evidenciado em face da propensão ao conflito entre os atores que o integram, manifestado pela acelerada organização de novas entidades, públicas e privadas, tais como as associações de classe dos médicos e as de defesa do consumidor, que contribuem para uma redistribuição do sistema de forças que interagem no setor.

No Brasil, a percepção, pelo governo federal, de que a ampla liberdade de mercado dos serviços privados de saúde pode ter concorrido para a formação de oligopólios - pelos fortes indícios de cartelização do setor -, prejudicando outros segmentos da economia e constituindo um perigoso fator de desequilíbrio no tecido social do país, ensejou a criação de uma entidade reguladora que se mantivesse relativamente eqüidistante do poder federal, das empresas concessionárias, das classes profissionais e dos consumidores dos planos de saúde, visando constituir uma zona de equilíbrio entre forças desiguais, com interesses tão distintos. Desse forma, o tema da assistência suplementar à saúde tem estimulado inúmeros estudos, tanto no Brasil quanto no exterior, que focalizam, principalmente, o aspecto técnico da estrutura física e a perspectiva dos efeitos adversos da lógica de mercado sobre os direitos sociais e os cânones do livre comércio.

Por outro lado, é inegável que, paralelamente aos fatores racionais, coexiste uma forte influência de componentes simbólicos, modeladores do modus operandi das organizações que integram o setor, consolidados em sistemas homogêneos de crenças e valores culturais, construídos socialmente ao longo de um histórico de interações no ambiente da política brasileira de saúde.

Com base na teoria do poder simbólico, este estudo visa contribuir para um maior entendimento quanto à formação dos espaços de poder e da consolidação do sistema de valores no campo da saúde suplementar no Brasil. Entretanto, levando em conta o continuum dos setores socais, é oportuno posicionar o ambiente da saúde suplementar no conceito de "campo", na medida em que as organizações que o integram tendem a se institucionalizarem, adotando regras, desenvolvendo competências e padrões de comportamento similares e próprios do seu contexto (SELZNICK, 1996).

Essa percepção advém da gradativa formação de estruturas autônomas e homólogas, com alto grau de coesão interna, tendentes a um modelo isomórfico que privilegia os valores e os mitos presentes nos respectivos contextos institucionais, legitimando-os e privilegiando-os, inclusive, com base nos cânones da eficiência técnico-empresarial. Isso caracteriza um padrão de comportamento que não se ajusta adequadamente ao conceito de "setor", no contexto deste estudo, visto que o mesmo deriva da visão das organizações como economias singulares, inseridas em setores industriais (SELZNICK, 1948).

Desse modo, a lacuna do modelo estruturalista quanto à força dos mitos sobre a eficiência foi completada quando se incorporou a visão das crenças, valores culturais, símbolos, mitos e normas que se institucionalizam no contexto das empresas, expandindo o conceito de ambiente organizacional, levando em conta que "os elementos simbólicos detêm o poder de transformar o ambiente, evoluindo de uma visão generalista para um enfoque simbólico", entendendo-se por símbolos as "palavras, gestos, imagens ou objetos que carregam um significado particular que é reconhecido somente pelos que compartilham a mesma cultura" (CARVALHO, VIEIRA e LOPES, 1999, p.9). Em outras palavras, da mesma forma que o ciúme, a raiva, o altruísmo e o amor identificam mitos que interpretam e explicam as ações dos indivíduos, os mitos dos médicos, dos contadores e dos trabalhadores da linha de produção explicam as atividades organizacionais às quais pertencem.

Por outro lado, existe uma impossibilidade de se definir as instituições, garantindo uma representação correta quanto aos seus específicos interesses. Injustiças, desigualdades e conflitos não são, necessariamente, reflexos dos fenômenos de dominação, mas, freqüentemente representam o produto da interdependência entre os 
agentes sociais e a impossibilidade de se definir a melhor organização dessa interdependência (BOUDON, 1979). De acordo com esse pressuposto, a simultaneidade dos princípios de divisão internos nas instituições segundo os quais se organizam os conflitos, as controvérsias, as competições e os limites historicamente determinados - está integrada à visão de campo simbólico de Bourdieu.

Quanto à ambiência do campo, esta é caracterizada por Heidegger e Merleau-Ponty (BOURDIEU, 2000, p.60), segundo os quais "os agentes sociais e os próprios dominados encontram-se unidos no mundo social, mesmo no mais repugnante e revoltante, por uma relação de cumplicidade padecida que faz com que certos aspectos desse mundo estejam para além ou aquém do questionamento crítico. Por meio dessa relação obscura de adesão quase corporal é que se exercem os efeitos do poder simbólico". Isso quer dizer que o efeito perverso, que faz com que alguém possa se abstrair em relação ao seu próprio interesse, evidencia que a lógica da ação coletiva e a lógica da ação individual não representam a mesma coisa (BOUDON, 1979).

Nesse sentido, o simbólico é um tipo de poder que se faz reconhecer e obter o reconhecimento, se faz ignorar em sua verdade de poder e de violência arbitrária, e cuja eficácia não se exerce no plano da força física, mas, sim, no do sentido e do conhecimento.

Bourdieu substitui a noção de sociedade pela de campo e espaço social, sendo que cada campo prescreve os seus próprios valores e princípios de regulação, no entendimento de que no mundo social ocorrem apenas relações, não interações entre agentes ou laços subjetivos entre indivíduos, mas, sim, relações objetivas que existem independentemente da consciência e do desejo individual.

Em outras palavras, o simbolismo presente na noção de campo permite compreender os relacionamentos entre o que é interno e o que é externo, cumprindo funções sociais externas, especialmente, de legitimação de uma ordem social, pelo simples fato de obedecer a uma lógica própria. Denominada por Bourdieu (2001a) de "habitus", essa lógica própria, por sua vez, pode ser influenciada pelo tipo de relações entre posições no campo, visto que estas conformam uma "estrutura estruturada e estruturante" que fornece as regras práticas para a sua ação, ao reproduzir as estruturas sociais e responder pelo pólo da ação. Portanto, Bourdieu concebe campo social como um ambiente de distintas e desiguais formas de poder, configurando um campo de forças e de lutas construído pela ação de agentes que se enfrentam com meios e fins diferenciados, segundo posições relativas em espaços de relações. O pressuposto é o de que "cada campo desenvolve valores particulares com base em princípios de regulação próprios, que delimitam um espaço socialmente estruturado no qual os agentes lutam, dependendo das posições que ocupam no campo, seja para mudar, seja para preservar seus limites e forma" (VIEIRA e MISOCZKY, 2001, p.10).

Por outro lado, Giddens (1998) diverge de Bourdieu ao afirmar que uma teoria da ação, embora precise lidar com as relações entre motivos, razões e propósitos, também deve oferecer uma explicação sobre a organização institucional e a mudança, entendendo que as propriedades estruturais das instituições não representam, apenas, coações sobre a ação, mas, são também incentivadoras desta, fazendo com que a racionalização reflexiva da ação opere por meio da mobilização de propriedades estruturais, contribuindo, ao mesmo tempo, para sua reprodução.

Assim, segundo Giddens, o campo, nas etapas iniciais do seu processo de formação, ainda não conformaria um padrão de homogeneidade. Porém, à medida que se estrutura e se institucionaliza, adquire estabilidade por meio de ações de indivíduos e do efeito de episódios cruciais ao longo da história da sua evolução, num processo gradativo de interação das organizações com a formação de estruturas interorganizacionais de dominação, geradoras de padrões de coalizão bem definidos.

Dessa perspectiva, foi considerado interessante ampliar o âmbito deste estudo, agregando uma abordagem complementar à teoria do campo simbólico, pela análise dos impactos das mudanças sociais geradas pela ação dos atores sociais, considerando-se os fatores histórico-institucionais do período em que se deu a consolidação do atual desenho do campo da saúde suplementar. 
Em termos metodológicos, a pesquisa valeu-se do levantamento histórico dos fatos relevantes na formação e estruturação do campo, bem como da tomada de detalhados depoimentos, colhidos em 32 entrevistas, no período entre 2000 e 2003, não só junto a representantes do governo ligados à regulação e ao controle da prestação de serviços de assistência à saúde, como também junto a entidades de classe e de mercado, cujas opiniões foram fundamentais para o entendimento das relações internas no campo.

A análise quantitativa identificou, por processos de comparação e medidas de associação, os padrões existentes entre as organizações que integram o campo, com base nos dados divulgados nas respectivas páginas na internet e nos cadastros da Agência Nacional de Saúde Suplementar (ANS).

A abordagem qualitativa aprofundou o conhecimento das relações sociais que levaram à atual configuração do campo, dos atores que o determinaram - de modo direto ou indireto -, como também dos processos e estruturas vigentes em momentos históricos relevantes.

O estudo avalia, subsidiariamente, a influência de outros tipos de entidades, como o Poder Judiciário, paralelamente às que também integram o campo, como a ANS, as instituições de defesa do consumidor (como o Procon e o Instituto Brasileiro de Defesa do Consumidor - Idec) e as de classe (como o Conselho Federal de Medicina). Na análise de conteúdo das entrevistas e discursos, foi aplicada a técnica interpretativa para a identificação das várias dimensões envolvidas no campo.

\section{A formação do campo da saúde suplementar}

No Brasil, a partir da Constituição Federal de 1988, a saúde foi legitimada como um direito de cidadania, assumindo o status de bem público, com base nos princípios do acesso, da universalidade, integralidade, hierarquização, descentralização e excelência na qualidade dos serviços ofertados a todos os cidadãos; os quais, entretanto, dependem de políticas públicas que costumam ir de encontro a interesses de organizações e instituições fortemente comprometidas com a sua mercantilização. Conseqüentemente, muitas das ações políticas, nacionais e internacionais, acabam formuladas sob pressão de interesses corporativos, contradizendo, política e ideologicamente, o paradigma de um sistema único de atenção à saúde.

A percepção sobre as oportunidades de exploração econômica da assistência à saúde começou na década de 1930, fortalecendo-se ao final dos anos 1950, quando o país começou a se industrializar e as instituições privadas consolidaram-se como as principais prestadoras de serviços hospitalares a uma nascente classe média. O Estado, por sua vez, iniciou programas voltados à centralização das ações de saúde, na busca de uma assistência indiferenciada à população, visando minimizar os deletérios efeitos sociais de uma estratificação econômica no campo da assistência à saúde. Desde então, a par do desenvolvimento econômico, o segmento privado de assistência à saúde tem integrado médicos, ambulatórios, hospitais, serviços diagnósticoterapêuticos, laboratórios e fornecedores de insumos. Esse processo consolidou prestígio, posição econômica e um alto padrão de serviços especializados, caracterizando-se, porém, pela contradição de apresentar altos custos com baixo impacto na saúde coletiva e de ficar concentrado nos grandes centros urbanos das regiões Sul e Sudeste, detentoras da maior parcela da renda nacional, afora outras regiões historicamente fortes na determinação política, como é o caso da Bahia (MARINHO, MORENO e CAVALINI, 2001).

Entretanto, "por mais estável que seja a economia de um país, os custos assistenciais são sempre impulsionados por forças expansionistas", como lembra José Mendes Ribeiro, pesquisador da Escola Nacional de Saúde Pública -ENSP, citado por Mesquita (2002), oriundas de inúmeros fatores como "a transição demográfica, a acumulação epidemiológica, a medicação societal, urbanização, a incorporação tecnológica, o crescimento da força de trabalho e o corporativismo empresarial e profissional", cujos efeitos, no Brasil, ensejaram uma forte intervenção do Estado, visando a uma assistência à saúde mais abrangente, pelo investimento na ampliação da rede de hospitais públicos. Isso resultou num novo perfil do mercado de serviços médicos, ao reparti-lo entre o Estado e as organizações privadas, representando um forte golpe na classe médica liberal, o que quase levou à 
extinção de uma atividade que se mantinha no país, de modo individualizado e modesto desde o século XVI, ao reduzir o poder político dos médicos.

Nesse aspecto, a partir da década de 1970, a luta envolvendo o poder médico, tanto no Brasil como nos EUA, com o surgimento das organizações burocráticas privadas, prestadoras de serviços de saúde, representou uma forte ameaça à classe dos profissionais de saúde. Essa ameaça decorre do fato de que as organizações empregadoras de médicos passaram a competir diretamente com os profissionais independentes, ao proporcionarem instalações e seguros próprios e submetê-los a condições desfavoráveis, com a redução de sua autonomia na fixação dos honorários e na tomada de decisões (MISOCZKY, 2001).

O confronto de interesses entre o Estado, a classe médica e os grupos privados de assistência à saúde nunca foi pacífico, e a alternância dos pólos de poder não tem sido neutra. À ascensão de alguns grupos, dá-se a queda de outros. No Brasil, o acirramento da concorrência no mercado de saúde suplementar e a prevalência das vantagens competitivas evidenciaram a vulnerabilidade dos consumidores, e, em vários casos, dos próprios profissionais de saúde, os efetivos prestadores dos serviços.

Desse modo, embora a teoria econômica neoclássica assuma o postulado da informação perfeita entre compradores e vendedores, no caso da saúde, o sistema lida com informações assimétricas, especialmente, na relação entre médicos e pacientes. Ou seja, os cuidados com a saúde não se acomodam à auto-regulação do mercado, que se afasta dos pacientes de alto custo, repassando-os à esfera do sistema de atendimento governamental (VIANA et al, 2002).

A assimetria de informações no sistema de saúde representa, de uma maneira geral, um fator de desequilíbrio de poder, conforme avaliado por Costa (2002), com base em dados do Banco Mundial, de 1995, cujos relatórios ressaltam sérias falhas no grau de informação e percepção do consumidor quanto aos seus direitos e à conduta devida às operadoras de planos de saúde, que, com frequiência, se voltam apenas para a clientela de baixo risco. Para Bahia e Viana (2002), esse processo de seleção adversa induz as operadoras no Brasil a deixarem sem cobertura, ou dependente do Estado, a população de risco elevado, que sofre de enfermidades crônicas, como as mentais, as cancerígenas e os soropositivos do HIV, dentre outras.

A necessidade de um contrapeso entre a eficiência econômica e a solidariedade social suscitou ações públicas de intervenção no setor, levando ao estabelecimento de normas que visam impedir que a competição encoraje seguradoras e operadoras de serviços de assistência à saúde a rejeitarem doentes fora do interesse econômico, como os de alto custo, os idosos e os pobres.

Entretanto, existem avaliações (CAMPOS et al, 2000) indicando que o espectro da intervenção governamental vai da doutrina do estatismo absoluto à total liberalização das forças de mercado, e que o Estado regulador situa-se no flange central desse espectro. Isso permite um vasto leque de opções quanto à ação regulatória e às formas de controle, refletindo o matiz ideológico que as fundamenta e o estágio de desenvolvimento do mercado que se pretende regular. Em ambientes maduros, a intervenção governamental tenderá a ser mais liberal, mantendo as condições de competição. Porém, no extremo oposto, o Estado proverá ativamente a oferta dos bens ou serviços escassos; tornando-se, no limite, o seu próprio produtor, caracterizando uma ação regulatória mais estruturante, como é o caso da assistência à saúde privada no Brasil.

Por outro lado, a ação do Estado no campo da saúde deve, forçosamente, levar em conta a existência de fatores subjetivos com elevada carga simbólica, identificados nos valores e sistema de crenças, a par do nível cultural. Da mesma forma, deve considerar as pressões advindas do contexto histórico de incertezas políticas e de injustiça social, no qual o conceito básico de cidadania começa a se fazer presente no vocabulário das pessoas simples, que crescentemente procuram os tribunais de justiça, na defesa de seus direitos. É nesse contexto que foi criada a ANS, nascida no bojo do processo de privatização dos monopólios naturais, como uma prestadora de serviços de utilidade pública intervindo num ambiente econômico bastante pulverizado e com baixa competitividade, fatores de ameaça a direitos e à qualidade dos serviços prestados. 
Campos (2000) alerta, porém, que, se por um lado, a criação de agências reguladoras reflete o consenso de não serem as forças do mercado capazes de, por si mesmas, dar a melhor destinação aos recursos da sociedade pelo menos. em determinados campos -, por outro lado, existe uma forte desconfiança quanto ao valor que a ação reguladora possa vir efetivamente a ter. No caso da saúde, embora haja consenso sobre a necessidade do poder público se fazer presente, é grande a preocupação com a possível manipulação do órgão regulador por interesses político-partidários, além de outros grupos de pressão pouco comprometidos com a melhoria da oferta dos serviços de saúde.

Segundo o modelo de representação de interesses de Richard B. Stewart (CAMPOS et al, 2000), as agências conformam arenas políticas nas quais grupos em competição tentam impor seus interesses específicos, influenciando a ação regulatória. A natureza e a qualidade da regulação efetuada estariam associadas à qualidade dos fluxos de informação no interior da agência, através dos quais se fariam conhecidos os diferentes interesses. Existiriam, portanto, três eixos comportamentais dos agentes interessados: não participar do jogo, participar de modo passivo ou tentar ativamente participar das decisões. Nessa última categoria seriam enquadrados os potenciais influenciadores do sistema.

Conforme esse entendimento, a saúde suplementar no Brasil reflete um ambiente de relações complexas, no qual um objetivo social relevante, como a saúde, depende fundamentalmente da resultante de um sistema de forças heterogêneas, antagônicas e não necessariamente comprometidas com a saúde das pessoas, e cujo controle, por parte do Estado, afigura-se instável.

\section{Os fatores históricos relevantes para a formação do atual desenho do campo}

Este estudo sinaliza que, no Brasil, a evolução do campo da saúde suplementar se deu a partir de reações de segmentos sociais às ações do Estado direcionadas para a universalização do acesso à saúde. A avaliação é a de que os eventos que efetivamente contribuíram para a formação do campo foram os seguintes:

- o início da industrialização do país, a partir da década de 1950, no governo de Juscelino Kubitscheck, com a institucionalização do parque produtivo por corporações estrangeiras que contrataram assistência privada para seus empregados, à semelhança de suas matrizes, visando garantir a produtividade de suas operações. Tal prática se propagou para outros setores, como algumas categorias de servidores públicos, estimulando a formação das primeiras organizações voltadas para a prestação de serviços privados de saúde;

- o Decreto-lei nº 200, instituído pelo governo militar de 1964, que viabilizou, em termos constitucionais, a contratação de empresas médicas para a implementação de programas e projetos de responsabilidade do Estado, estimulando a atividade empresarial na medicina, diante da preferência do governo pela contratação de convênios com empresas médicas, fomentando, com recursos públicos, o crescimento do parque privado de prestação de serviços de assistência à saúde;

- a recessão econômica da década de 1980, surgida no bojo da segunda crise do petróleo, em 1979, que acarretou a retração nos pagamentos dos convênios com empresas médicas, dando margem a que as organizações médicas, já consolidadas financeira e estruturalmente, passassem a fornecer diretamente seus serviços a indivíduos ou empresas;

- a outorga da Constituição Federal de 1988, que definiu a saúde como um direito universal da cidadania e dever do Estado, configurando um novo ator, o Sistema Único de Saúde (SUS), de fortíssima carga simbólica, ao qual coube gerir uma política una e integrada de saúde, descentralizando o financiamento da prestação dos serviços médicos, e, igualmente, estimulando as empresas médicas a também passarem a vender serviços à rede pública de saúde; e

- a reforma do aparelho administrativo do Estado, formulada e implementada na década de 1990, que resultou na regulação do campo da saúde suplementar, pela Lei nº 9.656, além da institucionalização da ANS, com a Lei $\mathrm{n}^{\circ}$ 9.961, instrumentos de intervenção direta do Estado no meio privado de assistência à saúde, com o objetivo de garantir tanto o equilíbrio e a solvência econômica do mercado quanto os direitos dos consumidores de planos privados de saúde. 


\section{Os atores do campo e respectivos recursos de poder}

Quanto aos atores, a pesquisa considera responsável pelo atual desenho do campo da saúde suplementar:

- a Agência Nacional de Saúde Suplementar (ANS), que tem o papel de regular o campo - com poderes auferidos pela legislação -, sua estrutura operacional de fiscalização com abrangência nacional, a independência administrativa e financeira, propiciada pelo sistema de mandato dos seus diretores e pela captação de taxas específicas das operadoras de planos de saúde, para o suporte financeiro às suas atividades;

- as operadoras de planos privados, que têm o papel de estruturar a prestação sistêmica dos serviços de saúde, contratando redes de assistência para o atendimento aos seus clientes. Nesse sentido, o poder desse ator está na sua estrutura organizacional, ampla e presente em toda a federação, assim como no poderio econômico que viabiliza eficiente lobby junto ao Poder Legislativo;

- os prestadores de serviços de assistência à saúde, que englobam a classe médica e as clínicas e hospitais de diagnóstico-terapêuticos, efetuando o atendimento aos detentores de planos de saúde, posteriormente remunerados pelas operadoras. O poder deste ator está na sua organização em conselhos e associações, na bancada formada por donos de clínicas e hospitais no Poder Legislativo e nos códigos de caráter ético, que brandem contra as operadoras e médicos contratados por estas; $\mathrm{e}$

- os consumidores de planos de saúde, que ainda não se estruturaram em sociedades civis para tratarem de questões lesivas aos seus direitos, mas que contam com entidades externas, como o Poder Judiciário, o Poder Executivo (através do Procon) e sociedades civis de caráter privado (como o Idec), que atuam, cada qual na sua esfera de competência, no sentido de salvaguardar direitos prescritos no Código de Defesa do Consumidor e na Lei $\mathrm{n}^{\mathrm{o}}$ 9.656, que dispõe sobre os planos privados de saúde.

Contudo, de uma perspectiva histórica mais ampla, o estudo sugere que outros atores, ao longo da história, igualmente contribuíram para a construção do campo, como é o caso:

- do governo federal, que, na busca pela universalização do atendimento à saúde, fomentou, em diferentes ocasiões, o surgimento e a expansão do setor privado, tanto pela contratação das emergentes empresas médicas, quanto pela abertura de linhas de financiamento subsidiado, voltadas ao seu crescimento estrutural, como ocorrera na década de 1920, com a Lei Eloy Chaves e o Decreto $\mathrm{n}^{\mathrm{o}} 5.109$, que expandiram a prestação de serviços médicos via contratação de terceiros. No regime militar, através do Plano de Ação para a Previdência Social (PAP) e do Fundo de Apoio ao Desenvolvimento Social (FAS). Na década de 1990, com a reforma do aparelho administrativo do Estado, que redefiniu o seu papel de regulador, garantidor de direitos sociais e promotor da competitividade, segundo a visão de que o espaço público é mais amplo do que o estatal;

- das corporações multinacionais estrangeiras, que, no início da industrialização do país, na década de 1950, estimularam a formação das primeiras entidades de prestação de serviços médicos, financiando, com recursos próprios, a contratação de médicos e a estrutura de atendimento interno nas fábricas, para prover diretamente assistência à saúde dos seus empregados, semeando um tipo de procedimento que se estendeu aos dias atuais, tal como se verifica atualmente pela existência das autogestões e dos convênios e contratos de organizações privadas com empresas médicas;

- das próprias organizações de serviços médico-hospitalares, que souberam aproveitar as fases de parceria com o Estado, e, que quando esta se rompeu, nos anos 1980, por conta da recessão macroeconômica verificada ao longo da década, migraram sua estratégia, recursos gerenciais e estrutura de atendimento para os consumidores privados, individuais e empresariais;

- da classe médica, que diante da consolidação das empresas prestadoras de serviços médicos inúmeras oriundas do setor financeiro - restritivas do caráter liberal do profissional de medicina, soube se organizar, seja através de operadoras de planos de saúde (caso da Unimed) concorrendo no mercado em igualdade de condições -, seja pelo fortalecimento de uma estrutura normativa e de representação, com a adoção de normas de conduta e de contratação do trabalho 
médico, como também pela atuação do Conselho Federal de Medicina (CFM) e da Associação Médica Brasileira (AMB);

O gráfico 1, relativo às interações internas e externas do campo da saúde suplementar, procura representar os espaços de poder entre as posições de cada ator, além das relações com outros ambientes de elevado conteúdo simbólico, dentre os quais sobressai o campo da saúde pública - que engloba o Sistema Único de Saúde (SUS) - e os campos dos poderes Judiciário e Legislativo. Estão representadas, ainda, instituições formais como o Ministério da Saúde; entidades públicas e privadas de defesa de direitos dos consumidores e o campo dos fornecedores de insumos médico-hospitalares.

\section{Gráfico 1}

Relações no campo da saúde suplementar

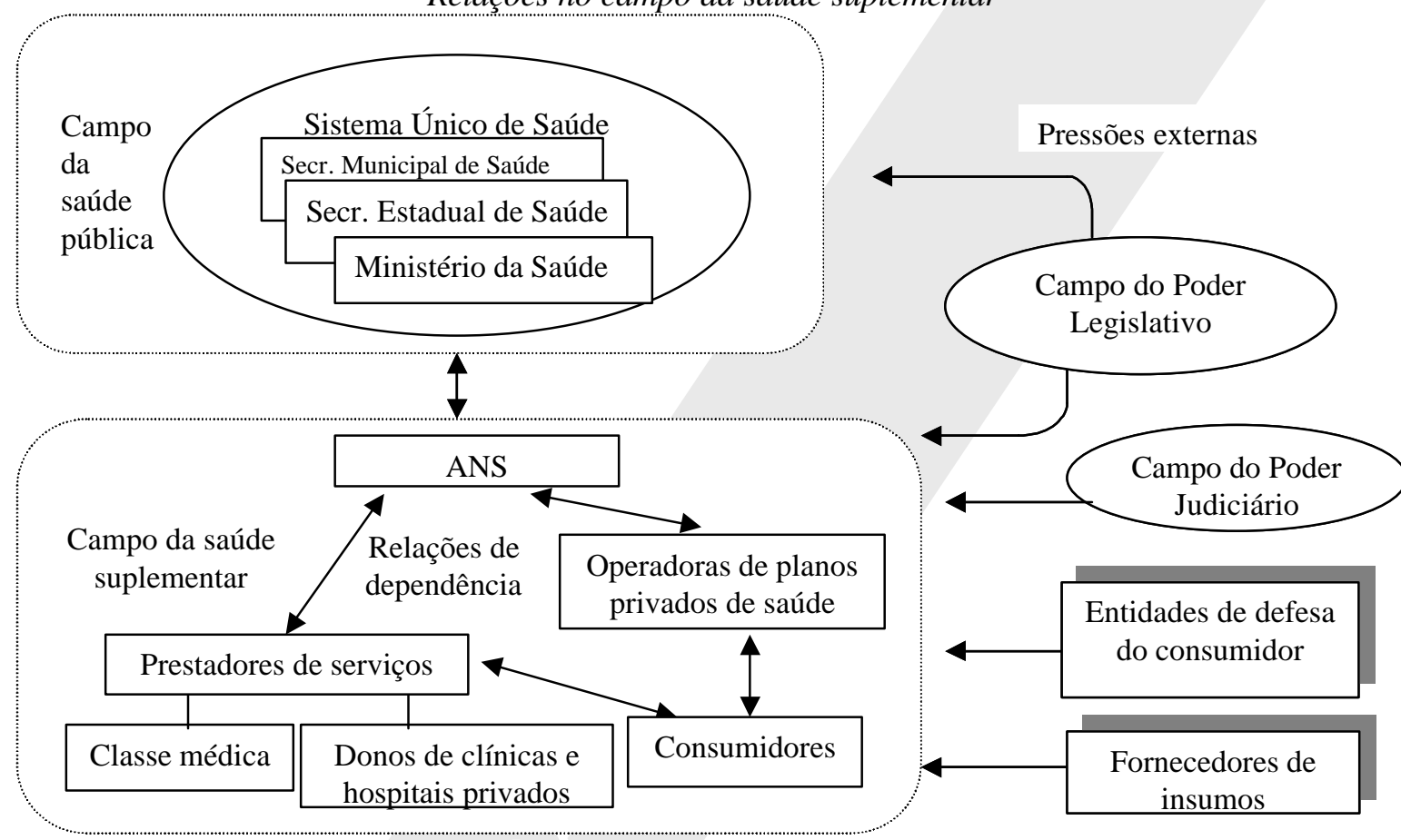

Bourdieu (2001b) define o campo político como um campo de lutas simbólicas, no qual os "profissionais da representação - em todos os sentidos do termo - se opõem a respeito do outro campo de lutas simbólicas", com base em um "poder de delegação, pelo qual o mandatário recebe do grupo o poder de fazer o grupo", constituindo-se numa pessoa ficta que "faz sair do estado de indivíduos separados o que ele pretende representar, permitindo-lhes agir e falar, através dele, como um só homem. Em contrapartida, ele recebe o direito de se assumir pelo grupo, de falar e de agir como se fosse o grupo feito homem".

Conforme esse entendimento, atualmente, o campo da saúde suplementar no Brasil é composto por atores representados por entidades afins, as quais interagem, entre si, na defesa dos seus interesses. O gráfico 2 procura oferecer uma visão do campo constituído pelos grupos de atores considerados relevantes e suas respectivas representações. 
Gráfico 2

As interações no campo da saúde suplementar

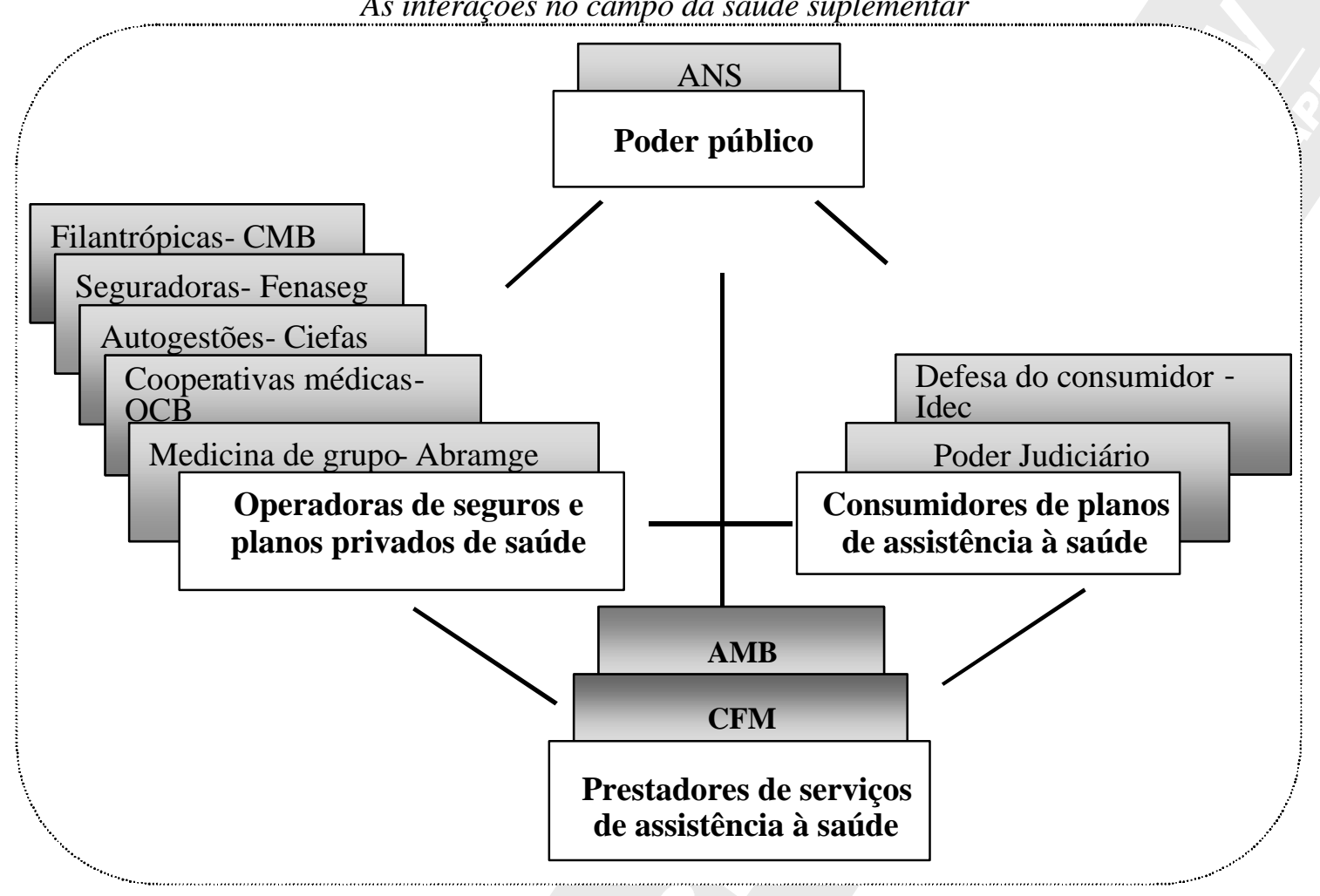

O campo da saúde suplementar compreende um conjunto de 2.723 operadoras de planos de saúde, cerca de 3.650 prestadores de serviços: hospitais (exceto clínicas de diagnóstico), consultórios e congêneres; um universo de 32.252 planos privados de saúde, para uma massa de 35 milhões de consumidores, girando recursos da ordem de $\mathrm{R} \$ 23$ bilhões. É um mercado bastante concentrado, na medida em que $80 \%$ dos consumidores têm contratos com apenas $12 \%$ das operadoras, sendo que $95 \%$ destes clientes estão na região Sudeste, principalmente, nas cidades de São Paulo e Rio de Janeiro, as quais, por si só, detêm $60 \%$ de todo o mercado (Brasil, 2002).

A segmentação das operadoras segue a seguinte tipologia: as medicinas de grupo, as cooperativas médicas, as autogestões e as seguradoras. Cada uma tem suas regras específicas de organização e funcionamento, sendo que algumas, a exemplo das Santas Casas de Misericórdia, podem ter fins lucrativos ou não. Por sua vez, a segmentação dos planos privados de saúde está divida em dois grandes grupos: por contratante e por tipo de contrato. No primeiro, estão os contratos coletivos, os coletivos por adesão e os individuais; enquanto no segundo grupo são encontrados os contratos ambulatoriais, hospitalares, obstétricos, odontológicos, fora o grande número de combinações entre estes.

O ambiente de forças políticas que interagem no campo da saúde suplementar, com base nos recursos de poder dos atores que o constituem, assemelha-se a um sistema de checks and balances, tendendo a um equilíbrio por vezes instável, visto que as posições de poder se alteram conforme as mudanças na política regulatória do campo ou do contexto macroeconômico do país, o que gera sensíveis reflexos nas estratégias desenvolvidas pelos atores para conquistar (ou garantir) seus respectivos espaços de poder.

O órgão regulador é representado pela ANS, por força da Lei $\mathrm{n}^{\circ} 9.656$, tendo atuado como um poder moderador no campo e procurado manter uma eqüidistância de interesses diante dos demais atores, inclusive, em relação ao Ministério da Saúde, ao qual é vinculado. O elo mais forte das interações no campo pertence ao eixo bipolar formado pela agência e as operadoras de planos privados de saúde. A força do órgão regulador reside no poder legal para impor resoluções, com o objetivo de garantir a solidez econômica das empresas de assistência 
médica, visando à solvência financeira do mercado em períodos recessivos, a padronização dos produtos a serem comercializados - para que não haja exclusões de renda, idade ou tipo de assistência ao consumidor de planos de saúde -, além de intervir diretamente na própria gestão das empresas de assistência médicohospitalar, tanto em caráter técnico e preventivo como em regime de liquidação extrajudicial. A agência também disciplina os elos de ligação entre os campos da saúde suplementar e da saúde pública, evitando que este seja explorado economicamente por aquele nos tratamentos dispendiosos.

A agência reguladora caracteriza um ator com valores que lhe são próprios e típicos de Estado, em conformidade com os ideais de justiça social - o tratamento desigual para os desiguais, na medida de suas desigualdades -, visando garantir o acesso das classes mais vulneráveis aos serviços privados de assistência à saúde. Eventualmente, associa simbolicamente as operadoras à imagem do comércio com motivação puramente lucrativa e afeita a práticas gerenciais ilícitas, que vulnerabilizam tanto os interesses sociais dos consumidores como a credibilidade do mercado da saúde suplementar, fatores relevantes que legitimaram a promulgação da Lei $\mathrm{n}^{\mathrm{o}}$ 9.656, instituidora da ANS.

Em contrapartida, as operadoras de planos de saúde - englobando as medicinas de grupo, cooperativas médicas, autogestões, seguradoras e entidades filantrópicas, dotadas de estruturas bastante similares, na forma de confederações nacionais, superintendências regionais ou escritórios locais, e atuação nos níveis federal, estadual e municipal - são representadas pela Abramge, Conamge, OCB, Ciefas, Fenaseg e CMB, respectivamente. ${ }^{1} \mathrm{Na}$ defesa de seus interesses, pressionando contra todos os demais atores do campo, segundo dados da pesquisa, as operadoras interagem, intensamente, contra os prestadores de serviço, os consumidores e, principalmente, contra o governo federal e a ANS.

A ação das operadoras de planos de saúde praticamente se dá por meio das empresas de elevado porte econômico, o que sugere uma forte tendência à constituição de oligopólios. Essas organizações seguem um discurso alinhado, não conflitivo entre si, identificando uma internalização de valores baseados em princípios próprios de auto-regulação, conforme a definição de espaço social de Bourdieu (2001b).

No relacionamento com os demais atores, as operadoras aplicam seus recursos de poder - fator econômico e estrutura organizacional - contra a ANS, de várias maneiras:

- pela argüição, junto ao Supremo Tribunal Federal (STF), da constitucionalidade de resoluções sobre reajuste de preços, no que eventualmente têm logrado êxito;

- pela concepção de novos mercados de consumo, para escapar do alcance jurídico da Lei no 9.656 , através de uma acelerada oferta de planos corporativos, modalidade não amparada pela citada lei, que trata apenas dos planos individuais e familiares;

- através de lobby junto ao Poder Legislativo, visando atenuar os rigores e a amplitude da legislação, caso do deputado Pinheiro Landin e dos inúmeros substitutivos ao projeto da Lei ${ }^{\circ}$ 9.656, que resultaram na redução das faixas de idade para fins de reajuste nos preço dos planos de saúde;

- através da mídia, pela barganha política com o governo, ameaçando deixarem sem cobertura milhares de beneficiários de planos de saúde, relegando-os à esfera do SUS, caso sejam pressionadas nas margens de lucro ou sofram demasiada intervenção por parte do Estado;

- em especial, as operadoras se destacam pela sistemática e orquestrada pressão contra a ANS, seja junto ao Conselho de Saúde Suplementar, em seminários ou na mídia, sempre associando o sistema público de saúde à ineficiência administrativa, lentidão e má qualidade de atendimento.

Contra os prestadores de serviço, as operadoras procuram reduzir o poder médico, assalariando-os e restringindo sua autonomia quanto à escolha de procedimentos médicos e ao padrão de relacionamento com os

\footnotetext{
${ }^{1}$ Abramge (Associação Brasileira de Medicina de Grupo), Conamge (Conselho Nacional de Auto-Regulamentação das Empresas de Medicina de Grupo), OCB (Organização das Cooperativas Brasileiras), Ciefas (Comitê de Integração de Entidades Fechadas de Assistência à Saúde), Fenaseg (Federação Nacional das Empresas de Seguro Privado e de Capitalização) e CMB (Confederação das Santas Casas de Misericórdia, Hospitais e Entidades Filantrópicas).
} 
clientes dos planos de saúde. Para isso, valem-se de inúmeras estratégias, tais como o descredenciamento de profissionais junto às redes de assistência, redução de honorários e glosas sistemáticas das faturas de pagamento pelos serviços prestados. No plano simbólico, as operadoras procuram associar a figura do médico a um velado interesse financeiro, fragilizando a imagem deste como agente humanitário, altruísta, que cura e salva vidas. A estratégia contra os prestadores também se dá na forma de lobby junto ao governo e à própria ANS, a qual chegou a acatar a tese do chamado "médico triador", que filtra os pedidos de exames de diagnóstico-terapêuticos, reduzindo o seu volume e barateando o sistema de custos, contido na Medida Provisória $n^{0}$ 2.177-43. Contudo, tal estratégia não logrou êxito, pela fortíssima reação de prestadores e consumidores, o resultando na retirada da MP da pauta de votação no Congresso, apenas uma semana após sua emissão.

Em contrapartida, a reação dos prestadores contra as operadoras é igualmente forte, agindo por meio do Conselho Federal de Medicina (CFM) e da Associação Médica Brasileira (AMB), com recursos de poder consistentes, brandindo os códigos de conduta e os processos éticos contra os médicos vinculados às empresas de saúde. Isso tem resultado numa estratégia eficaz, visto que tanto a prática como a comercialização da medicina não pode prescindir do profissional médico, o que faz subordinar, indiretamente, as operadoras à classe médica, como é o caso da Resolução CFM n ${ }^{\circ} 1.642$, responsável por inúmeros processos éticos contra médicos empregados das operadoras. No campo do simbólico, os prestadores associam as operadoras à caricatura do "capitalista de cartola e fraque", interessado tão somente nos lucros advindos dos serviços de saúde e insensível ao aspecto social. Os prestadores têm constantemente buscado a adesão dos consumidores, procurando demonstrar, igualmente recorrendo ao simbolismo, que as agruras destes têm origem nas operadoras, um inimigo comum de ambos, como na mensagem veiculada na mídia: "Planos de saúde. Enfiam a faca em você e tiram o sangue do médico!".

No eixo de poder entre operadoras e consumidores, a interação é igualmente conflituosa, em geral, por questões relacionadas com os preços dos planos de saúde e à exclusão de atendimentos por motivação econômica. Uma das estratégias desenvolvidas pelas operadoras contra os consumidores é o de restringir a frequiência de exames diagnóstico-terapêuticos, com um argumento fortemente calcado em simbolismos. Essa tática implica vincular os consumidores à imagem do "desperdício propiciado por pessoas hipocondríacas, que ocupam suas vidas, principalmente após a aposentadoria, com sucessivas visitas aos médicos, alimentando um ciclo vicioso de gastos, por saberem que o plano de saúde é obrigado a encampar todas suas despesas, não percebendo que encarecem o sistema como um todo e que, em última instância, são os próprios responsáveis pelos sucessivos aumentos dos preços dos planos de saúde". Em contrapartida, os consumidores, por intermédio de seus representantes, públicos e privados, como o Poder Judiciário, o Procon e o Idec, e com base nos recursos de poder constituídos pelo Código de Defesa do Consumidor e pela Lei $\mathrm{n}^{\mathrm{o}} 9.656$, reagem com denúncias junto ao órgão regulador e promovendo ações judiciais, com pedidos de liminares, interpretadas sob o enfoque consumerista. Essa atitude vem consolidando sólida jurisprudência sobre várias situações de lesão de direito, tais como a exclusão de atendimento por motivação de idade, por atrasos nas prestações dos planos ou por preexistência de doenças, dentre outros, norteando sentenças favoráveis ao consumidor e obrigando as operadoras ao cumprimento forçado dos contratos.

De um modo geral, o fluxo de interações no campo, embora desigual, é bastante intenso, como demonstrado na matriz de impactos cruzados dos atores, formada com base nos dados quantitativos das frequiências de ocorrência de certos elementos de mensagem e atitudes dos entrevistados, dispostos em escalas psicométricas de intensidade e sentido, segundo a metodologia da análise de conteúdo, de Bardin (1992).

Desse modo, percebe-se que o elo de interação mais intenso é aquele formado entre o governo/ANS e as operadoras de planos de saúde, o que pode ser interpretado como uma reação à recente instituição da ANS, atuante em um mercado até então livre da intervenção do Estado. A comunhão de interesses entre consumidores e prestadores, ambos atuando solidariamente contra as operadoras, é igualmente constatada. Por outro lado, percebe-se uma falta de sintonia política entre as áreas de saúde, em face do tênue alinhamento entre a ANS e o Ministério da Saúde, positivo mas fraco, demonstrando que a agência ainda carece de tempo para ser internalizada politicamente, com uma identidade própria, na esfera governamental. 
Quadro 1

Matriz de impactos de pressões - sentido $\uparrow \rightarrow$

\begin{tabular}{llllll}
\hline $\begin{array}{l}\text { Fatores de pres- } \\
\text { são }\end{array}$ & $\begin{array}{l}\text { Governo } \\
\text { (Ministério da } \\
\text { Saúde) }\end{array}$ & ANS & $\begin{array}{l}\text { Consumidores } \\
\text { de serviços de } \\
\text { saúde }\end{array}$ & $\begin{array}{l}\text { Operadoras de } \\
\text { planos de saúde }\end{array}$ & $\begin{array}{l}\text { Prestadores de } \\
\text { serviços de } \\
\text { saúde }\end{array}$ \\
\hline Governo & & $\begin{array}{l}\text { FRACA } \\
(+)\end{array}$ & $\begin{array}{l}\text { MÉDIA } \\
(+)\end{array}$ & $\begin{array}{l}\text { MUITO FORTE } \\
(-)\end{array}$ & $\begin{array}{l}\text { MÉDIA } \\
(-)\end{array}$ \\
\hline ANS & FRACA & & $\begin{array}{l}\text { MÉDIA } \\
(-)\end{array}$ & $\begin{array}{l}\text { MÉDIA } \\
(-)\end{array}$ & $\begin{array}{l}\text { FORTE } \\
(-)\end{array}$ \\
\hline Consumidores & INDIFERENTE & $\begin{array}{l}\text { FORTE } \\
(-)\end{array}$ & & $\begin{array}{l}\text { MUITO FORTE } \\
(-)\end{array}$ & $\begin{array}{l}\text { MÉDIA } \\
(+)\end{array}$ \\
\hline Operadoras & MUITO FORTE & $\begin{array}{l}\text { MUITO FORTE } \\
(-)\end{array}$ & $\begin{array}{l}\text { FORTE } \\
(-)\end{array}$ & $\begin{array}{l}\text { FORTE } \\
(-)\end{array}$ \\
\hline $\begin{array}{l}\text { Prestadores de } \\
\text { serviços }\end{array}$ & $\begin{array}{l}\text { FRACA } \\
(-)\end{array}$ & $\begin{array}{l}\text { MÉDIA } \\
(-)\end{array}$ & $\begin{array}{l}\text { MEDIA } \\
(+)\end{array}$ & $\begin{array}{l}\text { MÉDIA } \\
(-)\end{array}$ & \\
\hline
\end{tabular}

Fonte: Vilarinho (2003).

Onde:

\section{INTENSIDADE}

( Sentido )

Escala de intensidade e sentido: ${ }^{2}$

\begin{tabular}{|c|c|c|c|c|c|c|c|c|c|c|c|c|}
\hline Muito forte & $\leq$ & Forte & $\leq$ & Média & $\leq$ & Fraca & $\leq$ Indiferente & $\leq$ Fraca & $\leq$ Média & $\leq$ Forte & $\leq$ & Muito forte \\
\hline & $\leq$ & 3 & $\leq$ & 2 & $\leq$ & 1 & $\leq$ & $\leq$ & $\leq$ & $\leq$ & $\leq$ & \\
\hline
\end{tabular}

\section{Os mitos e crenças institucionalizadas no campo}

Os mitos, valores e crenças institucionalizados no campo da saúde suplementar foram identificados e correlacionados de acordo com a posição dos atores no campo, na visão de Bourdieu (2001b), dentre os quais ressalta o valor da saúde como prevalente sobre os demais. Sempre associado a uma categoria de direito inerente à sobrevida do homem, é um dos fundamentos da República, cláusula pétrea no artigo $5^{\circ}$ da Constituição Federal, com força tal que, na hipótese de um possível conflito de valores, como entre contratos de natureza econômica e a manutenção da vida, esta prevalecerá, afastando o mito do pacta sunt servanda, do direito contratual romano. O valor social da saúde também é fortemente utilizado pela classe médica, que o aplica contra as operadoras de planos de saúde como instrumento de legitimação de seus interesses econômicos, em sintonia com os interesses dos consumidores.

O valor da caridade também é muito visível no campo, principalmente, no âmbito das entidades filantrópicas caso das Santas Casas de Misericórdia - que, mesmo quando comercializam planos de saúde, têm o poder de assegurar tratamento diferenciado nos benefícios fiscais; embora, quando ameaçadas nesses interesses, reajam com a mesma intensidade das sociedades comerciais.

O mito da ineficiência administrativa do Estado, em contraposição ao da eficiência da iniciativa privada, é muito explorado pelas operadoras de planos de saúde contra a ANS e o SUS, embora isso seja minimizado pela crença popular na insensibilidade do capitalismo diante das questões sociais.

\footnotetext{
${ }^{2}$ A associação dos diferentes graus de intensidade das declarações dos entrevistados considerou não apenas os aspectos relativos à representatividade do cargo do informante em relação ao conjunto das organizações, mas também o impacto de certas palavras e expressões no ambiente culto da sociedade brasileira, conforme Bardin (1992).
} 
Assim, este estudo avalia que, no Brasil, o campo da saúde privada teve sua formação estimulada pelo Estado; sendo percebidas, várias situações de pressão da classe médica contra o governo e as organizações empresariais. No primeiro caso, pela redução da demanda de serviços particulares, em decorrência dos investimentos governamentais em hospitais, e pelo baixos salários dos empregos públicos. No segundo caso, pela perda de poder resultante da falta de autonomia de trabalho e pelo controle sobre os honorários médicos, situações que contribuíram para esvaziar o caráter liberal dos profissionais de medicina.

O estudo sugere que houve uma alternância entre modelos ideológicos de assistência à saúde - estimulada, direta ou indiretamente, por forte financiamento estatal -, dentre os quais sobressai o de defesa do acesso igualitário à saúde, pela sociedade, em oposição às políticas liberais, que defendiam um acesso diferenciado, segundo faixas de renda e postos de trabalho, privilegiando segmentos organizados da população, como os funcionários públicos e os empregados de empresas de grande porte.

É possível identificar uma sequiência de ciclos entre os dois modelos: em períodos anteriores ao primeiro quarto do século XX, o acesso à saúde ficou limitado a um restrito segmento de pessoas com poder aquisitivo para contratar médicos particulares- normalmente, nos grandes centros urbanos -, enquanto a extensa maioria da população simplesmente permanecia à margem da assistência médica, contando apenas com um escasso número de entidades filantrópicas e hospitais públicos. Não é por acaso que a expectativa de vida do brasileiro, na década de 1920, era de menos de 40 anos.

Houve uma tentativa de reversão desse sistema com o surgimento da Previdência Social, em 1923, e a criação da Caixa de Aposentadoria e Pensões, que contrastou com o liberalismo anteriormente dominante, em função do forte estímulo em favor do assistencialismo de massa. Nesse momento, no bojo da centralização previdenciária, ocorreu uma substancial elevação, tanto em qualidade quanto em amplitude, do grau de inclusão de segmentos da população até então sem acesso a sistemas de saúde.

Entretanto, esse progresso foi posteriormente bastante mitigado na era Vargas, no período entre 1930 e 1945 , ao se adotar o sistema de capitalização para a previdência, restringindo severamente os gastos com saúde por segurado, não obstante o volumoso crescimento da receita. Em contrapartida, uma vez restaurada a democracia com o governo Dutra, entre 1945 e 1950, buscou-se resgatar os antigos ideais igualitários da década de 1920, eliminando as contingências financeiras do regime anterior.

Contudo, com a industrialização do país, na década de 1950, o sistema universalista, enfraquecido mas ainda vigente, arrefeceu pela força de um renovado modelo de privilégios diferenciados. Promovido pelas recéminstaladas corporações multinacionais, por órgãos públicos e por empresas estatais, esse modelo proporcionou um inegável salto de qualidade nos tratamentos médicos e na tecnologia aplicada à saúde, sendo, entretanto, inatingível, para a massa de trabalhadores rurais e urbanos que não pertencesse a organizações com poder financeiro ou político forte o suficiente para desenvolver sistemas similares.

O golpe militar de 1964 trouxe, no bojo de um processo de centralização política e econômica, uma tendência de retorno ao modelo assistencialista, como mecanismo de compensação política e de suavização de tensões sociais. Visando legitimar o regime, tal processo implicou sólidos investimentos em hospitais públicos e o credenciamento de entidades privadas, privilegiando, apesar disso, a assistência individual e especializada, em detrimento de medidas de saúde pública, de interesse coletivo. Nesse período, recursos públicos financiaram substancialmente o parque empresarial da medicina, o que marcou o início da consolidação de seu poderio econômico.

Porém, mesmo enfatizando a visão política da gradativa ampliação do acesso à saúde às diversas camadas da sociedade, os graves acontecimentos econômicos internacionais do final da década de 1970 - como a crise do petróleo, que fez disparar a dívida externa do país, e a baixa infra-estrutura hospitalar -, puseram por terra o programa de universalização da saúde. Embora o modelo não tenha se completado, ficando aquém do planejado, teve, porém, o mérito de ampliar, até certo ponto, a inclusão social no sistema de saúde, na medida em que vários segmentos da classe média lograram acessar a saúde privada, em função da adesão de um maior número de empresas ao sistema de credenciamento de serviços de saúde 
Atualmente, embora o sistema de planos de saúde tenha se expandido, a pressão dos altos custos da tecnologia médica e a alta dos preços dos planos têm afastado amplos segmentos da classe média ou reduzido a qualidade dos serviços prestados. Isso significa que vem ocorrendo um retorno ao modelo elitista de privilégios, desenhado para restritos grupos de pessoas com sólidos recursos ou que estejam hierarquicamente bem posicionadas em organizações de grande porte, financiadoras de planos executivos compatíveis com os altos custos da moderna e sofisticada tecnologia médica.

A proliferação dos planos coletivos evidencia o empobrecimento dos segmentos de média e baixa renda para que possam aderir a planos individuais e familiares. Isso revela que a solução de um problema social de grandes proporções vem sendo postergada, visto que apenas quem está empregado participa dos planos coletivos.

Segundo Ana Amélia Camarano, pesquisadora do Instituto de Pesquisa Econômica Aplicada (Ipea), estima-se que em 2020 existirão cerca de 28 milhões de idosos, com idade acima de 60 anos; uma massa de aposentados fora do mercado e dos planos de saúde coletivos, e, muito provavelmente, sem condições econômicas para sustentar os preços dos futuros planos individuais de saúde. Ou seja, um contingente equivalente, nos dias de hoje, à atual população economicamente ativa (PEA), que ficará à margem da assistência médico-hospitalar privada, procurando refúgio no SUS e configurando um novo formato de excluídos sociais dos serviços de saúde.

O gráfico 3 procura dar uma visão dos ciclos de vida dos sistemas assistencialista e de privilégios, que se alternaram no campo da saúde suplementar no Brasil.

Gráfico 3

A evolução do campo da saúde suplementar

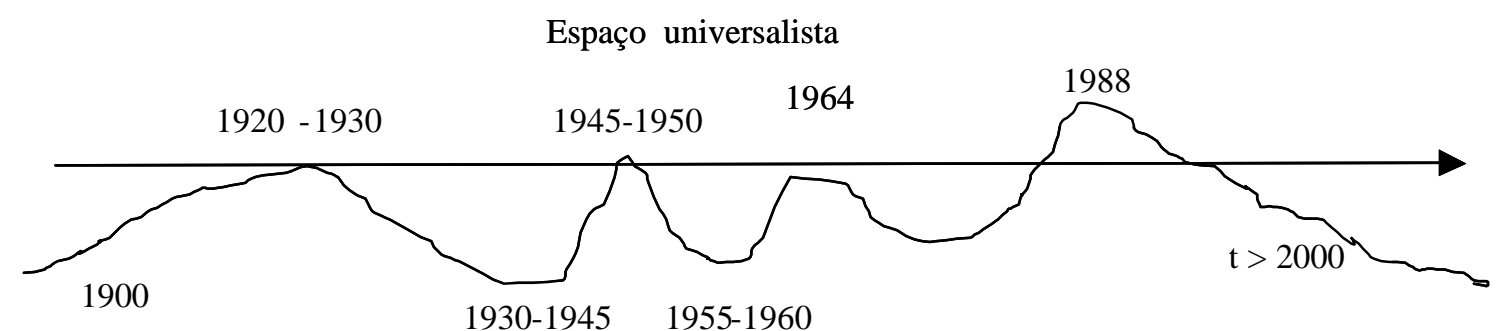

Espaço de privilégios

tempo

\section{Conclusões}

A pesquisa demonstrou que os atores do campo da saúde suplementar estão organizados em estruturas bastante similares entre si. Os consumidores de planos de saúde são exceção, pois ainda dependem de órgãos governamentais e de algumas poucas entidades privadas para a defesa dos seus interesses. Porém, quanto às operadoras, aos prestadores de serviço e à própria ANS, foi identificada uma homologia entre modelos organizacionais, evidenciando que, em sua maior parte, o campo modelou um sistema de mitos, valores e crenças, de base simbólica, que utiliza em suas relações de poder, parecendo estar consolidado após um processo evolutivo de constituição.

Quanto às pressões internas, o estudo avalia que as operadoras e a ANS formam o eixo de maior intensidade nas interações no campo. As operadoras, como ator social, são o agente mais controvertido, recebendo pressões de praticamente todos os demais, com igual intensidade de força e sentido. Os prestadores são aliados dos consumidores contra as operadoras, enquanto a ANS, às vezes, parece tender para os interesses das operadoras. Cabe ressaltar, no entanto, que um dos objetivos estratégicos da agência é garantir a solvência do mercado, visando à operacionalização do sistema privado de saúde. Essa aparente ambiguiidade de ações, por parte da ANS, tem sido responsável por fortes críticas de consumidores e prestadores de serviço, que buscam direcionar o poder da agência contra o seu mais visível oponente, no caso, as operadoras de planos de saúde. 
O campo reflete matizes de cunho ideológico desde sua formação, alternando influências de cunho social - ao se aproximar do modelo do welfare state - com fases de liberalização econômica. As perspectivas futuras apontam para uma hegemonia do parque privado, pela sintomática escassez de recursos do Estado. No entanto, é possível que o liberalismo acabe assimilando a questão social, pela pressão psicológica das forças sociais, tal como atualmente ocorre nas empresas de autogestão. Sem descurar da finalidade lucrativa, essas empresas têm investido recursos na assistência a seus empregados, fortalecendo um movimento de parceria entre o público e o privado que tende a crescer, o que poderá reverter a expectativa de crise do sistema privado de saúde.

\section{Referências bibliográficas}

BAHIA, L; VIANA. A. L. Regulação e saúde - estrutura, evolução e perspectivas da assistência médica suplementar. Rio de Janeiro: ANS/M inistério da Saúde, 2002. (Nota sobre a regulação dos planos de saúde de empresas no Brasil. Série C. Projetos, Programas e Relatórios, n.76).

BARDIN, L. Análise de conteúdo. Editora Edições 70, 1992.

BOUDON, R. Efeitos perversos e ordem social. Rio de Janeiro: Zahar Editores, 1979.

BOURDIEU, P. 0 campo econômico. A dimensão simbólica da dominação. Campinas: Papirus, 2000.

A economia das trocas simbólicas. São Paulo: Perspectiva, 2001a.

0 poder simbólico. Rio de Janeiro: Bertrand Brasil, 2001b.

BRASIL. Agência Nacional de Saúde Suplementar. Disponível em: <http:// www.ans.gov.br >. Acesso em: out. 2002.

CAM POS, A. M. Avaliação de agências reguladoras: uma agenda de desafios para a sociedade brasileira. Revista de Administração Pública - RAP, Rio de Janeiro, v.34 n.35, set./out. 2000.

et al. Bases para o desenvolvimento de um sistema para controle e avaliação da Agência Nacional de Saúde Suplementar. In: Propostas de alternativas organizacionais para o processo de regulação de planos e seguros privados no Brasil: subsídios à avaliação e aperfeiçoamento da ação reguladora da Agência Nacional de Saúde Suplementar - ANS. Rio de Janeiro: ANS, 2000). (Documento interno).

CARVALHO, C.;VIEIRA, M. M.; LOPES, F. D. Contribuições da perspectiva institucional para análise das organizações. In: ENCONTRO ANUAL DA ANPAD, 24., Foz do Iguaçu, 1999. Anais... Foz do Iguaçu: Anpad, 1999.

COSTA, N. et al. As agências de regulação independentes. In: Regulação e saúde - estrutura, evolução e perspectivas da assistência médica suplementar. Rio de Janeiro: ANS/M inistério da Saúde, 2002. (Série C. Projetos, Programas e Relatórios, n.76).

GIDDENS, A. Política, sociologia e teoria social - encontros com o pensamento social clássico e contemporâneo. São Paulo: Fundação Editora da Unesp, 1998.

MARINHO, A.; MORENO, A.; CAVALINI, L. Avaliação descritiva da rede hospitalar do Sistema Único de Saúde - SUS. Rio de Janeiro: Ipea, 2001. (Texto para discussão n. 848, ISSN 1415-4765).

MESQUITA, M. A. A regulação da assistência suplementar à saúde: legislação e contexto institucional. In: Regulação e Saúde - estrutura, evolução e perspectivas da assistência médica suplementar. Rio de Janeiro: ANS/Ministério da Saúde, 2002. (Série C. Projetos, Programas e Relatórios, n.76).

MISOCZKY, M. C. Campo de poder e ação em Bourdieu: implicações de seu uso em estudos organizacionais. In: ENCONTRO ANUAL DA ANPAD, 25., Campinas, 2001. Anais... Campinas: Anpad, 2001.

SELZNICK, P. Foundations of the theory of organization. American Sociological Review, v. 13, p.25-35, Feb. 1948. . Institucionalism "old" and "new". Administrative Science Quarterly, v.41, p.270-277, 1996.

VIANA, A. et al. Estado e regulação da saúde. In: Regulação e Saúde - estrutura, evolução e perspectivas da assistência médica suplementar. Rio de Janeiro: ANS/M inistério da Saúde, 2002. (Série C. Projetos, Programas e Relatórios, n.76).

VIEIRA, M. M.; MISOCZKY, M. C. Instituições e poder: explorando a possibilidade de transferências conceituais. In: ENCONTRO ANUAL DA ANPAD, 25., Campinas, 2001. Anais... Campinas: Anpad, 2001.

VILARINHO, P. F. A formação do campo da saúde suplementar no Brasil. Rio de Janeiro: (Dissertação de mestrado) - Ebape, Fundação Getulio Vargas - FGV. 2003. Disponível em: <www.ebape.fgv.br/academico>. 